\title{
ANILLOS ALREDEDOR DEL SOL
}

\section{RINGS AROUND THE SUN}

Trudy E. Bell: Universidad Politécnica de Nueva York en Brooklyn (Estados Unidos) trudy.bell@gmail.com

\section{CURRÍCULUM VITAE}

Licenciada en historia por la Universidad de California en Santa Cruz (Estados Unidos) y Doctora en historia de la ciencia por la Universidad de Nueva York (Estados Unidos). Profesora en varias Universidades y empresas de literatura científica como la Universidad Politécnica de Nueva York en Brooklyn (Estados Unidos). Divulgadora científica en varias publicaciones y colaboradora con varias editoriales y OO.NN.GG.

\section{RESUMEN}

Los cristales de hielo en la atmósfera terrestre no sólo crean anillos alrededor del Sol, sino también anillos alrededor de la Luna, perros lunares y hasta Pilares de Venus. Si usted ve un pilar solar o un halo poco antes de que se oculte el Sol, esté alerta para ver anillos y pilares alrededor de objetos del cielo nocturno unas cuantas horas después. Este artículo es la experiencia que vivió su autora al respecto de los anillos alrededor del Sol.

\section{PALABRAS CLAVE}

Anillos - Sol - Cristales de hielo - Cielo 


\begin{abstract}
Ice crystals in the atmosphere not only create rings around the sun, but also rings around the moon, lunar and even dogs Pillars of Venus. If you see a halo or a solar pillar just before the sun sets, be alert for rings and pillars around objects in the night sky a few hours later. This article is the experience that the author lived about ring around the sun.
\end{abstract}

\title{
KEY WORDS
}

Rings - Sun - Ice Crystals - Heaven

TEXTO:

En cualquier lugar donde haya Sol y nubes en el cielo, asegúrese de mirar hacia arriba: ¡podría usted ver anillos, arcos y otras maravillas!

Octubre 24, 2002: Fue justo después del almuerzo aquél 25 de septiembre, cuando salí hacia el patio trasero de mi casa en Ohio. Qué espléndido atardecer de otoño. El azul pálido del cielo estaba rayado por mechones de cirros. El Sol se hallaba alto y brillante.

Miré entonces hacia arriba... El Sol estaba rodeado por un halo extraordinariamente brillante, con los colores del arco iris. Flanqueándolo a derecha e izquierda se hallaban dos brillantes "perros solares" (en inglés sun dogs), con forma de cometa y también coloreados como un arco iris (estos fenómenos se conocen técnicamente 
como parhelia, palabra que proviene de palabras griegas que significan "detrás del Sol"). ¡Fenomenal!

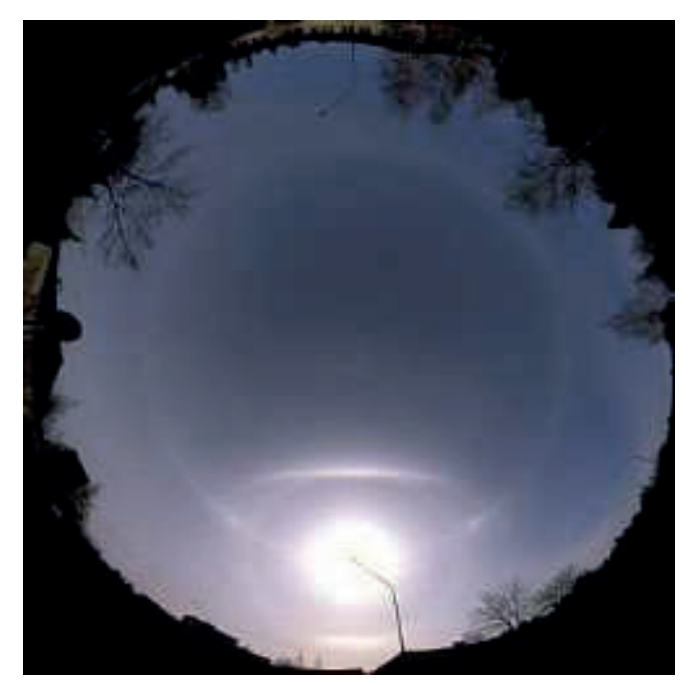

Esta escena, grabada en Finlandia por Pekka Parviainen usando una lente gran angular, es parecida a la que el autor Trudy E. Bell observó en Ohio el mes pasado. Un "halo circunscrito" en forma de balón de futbol americano rodea al Sol. Un "círculo parhélico" más tenue encierra al horizonte. "Nunca había visto algo tan grande y tan perfectamente circular", dice Bell.

Me dirigí entonces al patio delantero, que tiene una mejor vista del cielo, y comencé a girar para ver hasta dónde llegaba la "cola de cometa" de los perros solares. Di una vuelta de $360^{\circ}$, y accidentalmente perdí el equilibrio y caí sobre la hierba. No sólo había un halo alrededor del Sol -el llamado "halo de $22^{\circ \text { " }}$ que los observadores del cielo ven frecuentemente-, sino que también había un enorme anillo de luz corriendo en forma paralela al horizonte, a la misma altura que el Sol. Era como un gigantesco halo angelical suspendido sobre mi pueblo, interrumpido cada $120^{\circ}$ por una brillante salpicadura de luz (más "perros solares"). "Este es el círculo parhélico completo!", exclamé en voz alta en la calle vacía.

Toda aquella mañana había estado saliendo fuera de mi casa cada hora para mirar al cielo, porque sabía que aquellas tenues nubes cirros con aquella brillante luz solar, 
eran casi una garantía de que vería algo maravilloso. Las nubes tipo cirros están hechas de millones de cristales hexagonales de hielo y se localizan a alturas de 5 a 10 $\mathrm{km}$ en la troposfera, donde los aviones vuelan - cada cristal actúa como un prisma en miniatura, refractando (doblando) la luz del Sol y enviándola de regreso a la atmósfera en todas direcciones-. Debido a que la parte superior de la troposfera se encuentra casi siempre a temperaturas por debajo del punto de congelación, los cristales de hielo pueden ser observados a lo largo de todo el año (yo he visto tenues perros solares aun en julio). Pero despliegues realmente insólitos en los Estados Unidos, son más comunes en el otoño, el invierno y en la primavera, cuando la corriente de chorro del norte desciende hacia el sur, trayendo masas de aire ártico que cargan consigo como joyas, un tesoro de prismas de hielo.

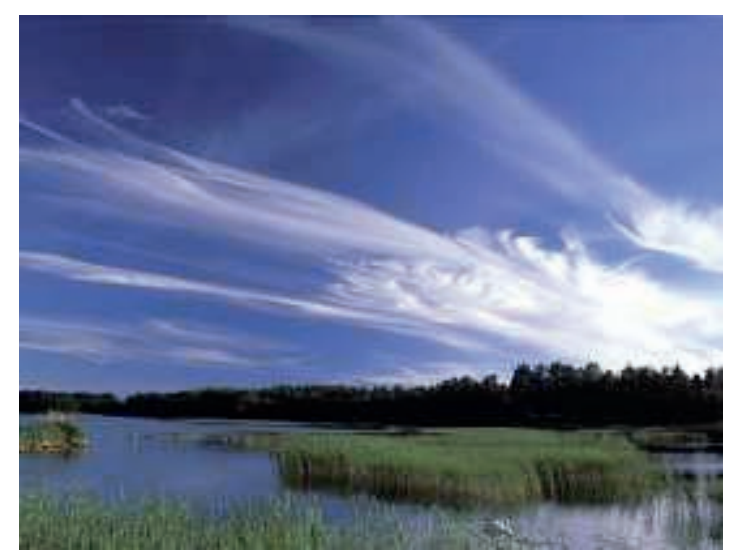

Nubes de gran altura con forma de mechón, como éstas, contienen cristales de hielo que causan la formación de halos solares. Crédito: Pekka Parviainen

Justo entonces, mi vecina Cindy sacó su camioneta en reverso fuera de su estacionamiento. La llamé y apunté hacia arriba. Ella salió de su vehículo y miró hacia arriba. Sus ojos se abrieron amplios y dejó caer la quijada. "¿Habían predicho esto?", preguntó entusiasmada. "¿Sabía la gente que esto iba a pasar? ¿Cómo sabes cuándo hay que mirar?" 
No, expliqué, los despliegues atmosféricos no pueden ser previstos del modo que los astrónomos predicen las fechas y horas de las tormentas de meteoros o los eclipses. El observar un espectáculo de luz como éste es más parecido a ver volar alguna inusual ave migratoria sudamericana en Ohio: es saber generalmente cuáles son las condiciones climatológicas ideales y la época del año; simplemente tienes que confiar en tu suerte.

No sólo eso, sino que cada despliegue de cada cristal de hielo es tan diferente como cada patrón de un caleidoscopio - y por razones similares-. Los despliegues en el cielo de día dependen de la inclinación de los cristales de hielo en el aire y de la altitud del Sol. Los despliegues dependen de si los cristales de hielo son como platos planos o como lápices alargados. Dependen también del tamaño de los cristales. Aquellos cristales que son demasiado pequeños o imperfectos no pueden actuar como prismas. Pero si los cristales son de una excepcional calidad, casi como joyas, el domo entero del cielo diurno puede acabar festoneado con exóticos halos, bucles, arcos y cruces -jo el círculo parhélico completo brillando ahora sobre nuestras cabezas en una silente gloria!- "Y pensar que" -remarcó Cindy, volviéndose a subir a su camioneta-, "¡yo no hubiese notado nada de esto si tú no me hubieras hecho mirar hacia arriba!"

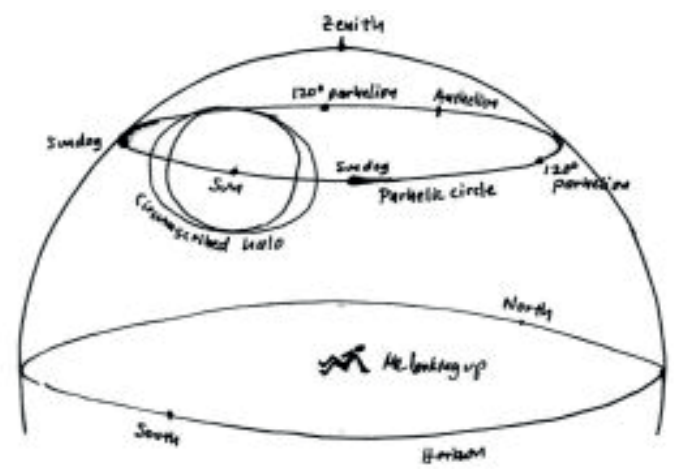

La autora Trudy Bell hizo este boceto en 3 dimensiones del círculo parhélico que observó el 25 de septiembre del 2002. 
Cuando mi amiga se alejó manejando, me quedé pensando en sus preguntas y en su comentario.

Aunque he sido una ávida astrónoma aficionada y amante del cielo nocturno desde 1965, hace apenas cinco años que me volví también devota del cielo diurno. Durante ese tiempo, mi experiencia me ha revelado que aun supuestos raros despliegues de óptica atmosférica, son más comunes de lo que indican los libros de meteorología - y completamente visibles para cualquiera a quien simplemente se le ocurra inclinar la cabeza hacia arriba-.

Ahora que he cultivado el hábito de mirar hacia arriba una docena de veces al día, rara vez ha pasado una semana en que no obtenga mi recompensa - ya sean halos solares, perros solares, rayos crepusculares (astas de rayos solares y sombras saliendo de atrás de hinchadas nubes cumulos), arcos circumcenitales (un "arco de hielo" coloreado como un arco iris que forma un medio círculo alrededor del cenit), pilares solares, ó ahora, el círculo parhélico completo-.

Sí, el cielo diurno abunda en regalos inesperados, que pueden ser suyos con sólo tomar un momento ipara mirar hacia arriba!

Nota del editor: Los cristales de hielo en la atmósfera terrestre no sólo crean anillos alrededor del Sol, sino también anillos alrededor de la Luna, perros lunares y hasta Pilares de Venus. Si usted ve un pilar solar o un halo poco antes de que se oculte el Sol, esté alerta para ver anillos y pilares alrededor de objetos del cielo nocturno unas cuantas horas después.

\section{Créditos y Contactos}

Autor: Trudy E. Bell 
Funcionario Responsable en NASA: Ron Koczor

Editor de Producción: Dr.Tony Phillips

Curador: Bryan Walls

Relaciones con los Medios: Steve Roy Traducción al Español: Carlos Román Traducción de Gráficas: Boris G. Simmonds

Editor en Español: Héctor Medina

El Directorio de Ciencias del Centro Marshall para Vuelos Espaciales de la NASA patrocina el Portal de Internet de Science@NASA que incluye a Ciencia@NASA. La misión de Ciencia@NASA es ayudar al público a entender cuán emocionantes son las investigaciones que se realizan en la NASA y colaborar con los científicos en su labor de difusión.

Más Información (en inglés)

Óptica Atmosférica. Una guía completa acerca de los perros solares, halos y pilares. Estas secciones son de particular interés: comenzando; sugerencias para fotografía; ¿Qué tan poco frecuentes son los halos y por qué?

Halos, pilares y perros solares pueden ocurrir durante cualquier estación. "Los cristales de hielo que los causan se forman en nubes de gran altitud a $5 \mathrm{~km}$ o más sobre la superficie de la Tierra, donde la temperatura siempre es gélida", dice Bruce Wielicki, un científico atmosférico del Centro de Investigaciones Langley (Langley Research Center) de la NASA.

Robert Greenler, Arco Iris, Halos y Glorias, con un catálogo completo de formas de cristal de hielo, y los despliegues que producen, además de útiles fotografías a color de muchos tipos de despliegues que se pueden observar. (Este es un libro clásico, hoy fuera de imprenta, pero ampliamente disponible en las bibliotecas). 
Únase a nuestra creciente lista de suscriptores - anótese para recibir nuestro servicio de entrega inmediata de noticias científicas- y jreciba un mensaje de correo electrónico cada vez que publiquemos un nuevo artículo! 